More problems than products

FOR a nominally fast-growing field, biotechnology had a supremely disappointing year. In the United States, just one new product won government approval (Genentech's gamma interferon, just a week ago). And the year ahead is clouded by fears that the use of genetic engineering to manufacture L-tryptophan in a nutritional supplement may have caused cases of a rare and sometimes fatal blood disorder in the United States (see below).

The US industry during 1990 was preoccupied with a paroxysm of takeovers and mergers, the chief of which was the purchase by Swiss-based Roche of a 60 per cent stake in Genentech, Inc. Other companies were busy forming strategic alliances in Europe and Japan.

Only Genentech and Amgen, Inc. produced meaningful profits in 1990; most US companies have yet to break even. What 1990 showed is that a company's failure to win product approval the first time round can be costly, as Cetus Corporation found when denied approval for interleukin-2 in July. So can protracted patent litigation witness the interminable patent dispute between Amgen and Genetics Institute, Inc. over rights to erythropoietin.

If dissension in the ranks is the sign of trouble, biotechnology's problems may

\section{Engineering trouble?}

THE trouble over L-tryptophan has sent shivers through the biotechnology industry. The material is made by the Japanese chemical company Showa Denko and has been implicated in more than 1,500 cases of eosinophiliamyalgia syndrome (EMS) in the United States, including 27 deaths. If Showa Denko's use of genetic engineering is found to be related to the EMS outbreak, the consequences for the industry could be devastating.

US and Showa Denko researchers have traced the possible cause of the EMS outbreak to a contaminant that appears only during the purification of L-tryptophan; the contamination is not present during earlier stages of manufacture when genetically-engineered bacteria produce the amino acid in a fermentation broth.

But biotechnology is not yet off the hook because it has yet to be shown that the contaminant, di-tryptophan aminal acetaldehyde (DTAA), causes EMS. Nor has it been firmly established that the appearance of DTAA during purification is unrelated to the use of genetically-engineered bacteria earlier in the manufacturing process. Animal experiments now under way in the United States and Japan may help resolve the issue. get even worse. Last March, Cetus and Genetics Institute noisily quit the Industrial Biotechnology Association (IBA), claiming that the association had taken sides on several key issues. The only significant piece of US legislation, an amendment of the Orphan Drug Act, was given a mixed reception by the industry, then killed by President George Bush.

One genetically-engineered product that might have turned an honest penny was bovine somatotropin (BST), which boosts milk production in cows. But that market dried up when the major milkproducing states in the United States followed the decision of the European Communities and banned the material on economic and health grounds. These decisions were not shaken by the unprecedented step of the US Food and Drug Administration last August in publishing human food safety data while the review of data was still under way. Even the clean bill of health given to the hormone last month by an NIH panel has not exorcised the doubts of consumer lobby groups and animal welfare organizations.

One of the few bright spots in 1990 was the successful first trial of gene therapy to treat a human disease, that of a 4-year-old girl suffering from a rare inherited immune system disorder, adenosine deaminase (ADA) deficiency. A second study, also at NIH, will treat patients with advanced malignant melanoma.

US experience has mostly been mirrored elsewhere, in Europe for example. But there has been some progress with the development of regulations, notably in Germany. Despite the country's conservative stance on embryo research and gene therapy involving the human germline, a law to regulate the use of genetic manipulation in laboratory research and industrial production was passed in June.

Both researchers and pharmaceutical companies are relieved. Hoechst now expects to be able to finish the human insulin pilot plant it had been building near Frankfurt until the courts ordered a halt to the work pending the passage of a law. The technique is, of course, identical with that used elsewhere for almost a decade.

In Switzerland, by contrast, some researchers fear that more restrictive regulations may emerge from discussions now under way in the federal parliament. Proposals that genetic manipulation should be allowed only when it can be shown to be of "immediate medical beferenda. The fear is that parliamentary procedures may require these propositions to be reflected in laws due to be drafted in the New Year. Such a move, however improbable, would halt not just biotechnology but molecular biology. nefit" have won support in cantonal re-

\section{More monkey business}

THE most celebrated icons of the US animal-rights movement - the 'Silver Spring monkeys' - began and ended 1990 (see also page 13). After nearly a decade of legal and administrative fighting, NIH scientists started the year by experimenting on and then killing one of the eight then remain-ing; in July, three of the rest were simi-larly killed after experiments, as required by the regulations. By the end of the year, the fate of the remaining four was headed for the Supreme Court.

While the philosophical debate seems no closer to resolution, 1990 may nevertheless be remembered as the year in which the US scientific community mobilized its defence. Both NIH and its sister agency, the Alcohol, Drug Abuse and Mental Health Administration, started new public education programmes to promote the value of animal research. A number of drug companies and medical supply houses made plans for a similar effort of their own.

Animal welfare is another issue on which 1990 proved also to be frustrating. New regulations - the long-awaited amendments to the Animal Welfare Act - were aired for public comment by the Department of Agriculture, which handles animal issues in the United States.

Although final rules for small mammals were eventually approved, the most contentious regulations - those governing dogs, cats and primates - were held up by a lengthy battle inside the administration over the flexibility that should be allowed to research laboratories on the size of cages and exercise requirements. The final regulations, due next month, are likely to be "performance based", meaning that the health of the animals will be the essential criterion, not the details of their housing. Activists consider such regulations unenforceable and are threatening to sue, claiming allies in the Congress.

In Britain, the animal-rights debate took a sinister turn in June when a Ministry of Defence veterinary officer and a University of Bristol neurophysiologist were targeted in car bomb attacks. Neither was seriously hurt. But the violence, and the realization that the more moderate animal rights groups are making inroads with young people, prompted the scientific community to join the debate.

British animal experimenters will have to battle not only for public sympathy, but also for public funds. Universities estimate that upgrading animal houses to comply with 1989 guidelines will cost $£ 75$ million, but the government promises only an extra $£ 10$ million a year over the next three years. Some facilities may be forced to close. 